\title{
A Case-Control Study of Tackle-Based Concussion Risk Factors in The National Rugby League
}

\section{Andrew J Gardner ( $\sim$ Andrew.Gardner@newcastle.edu.au )}

The University of Newcastle Faculty of Health and Medicine

\section{Grant Iverson}

Harvard Medical School

\section{Suzi Edwards}

University of Newcastle - Ourimbah Campus: The University of Newcastle - Central Coast Campus

\section{Ross Tucker}

World Rugby

\section{Original Research Article}

Keywords: Tackle, injury prevention, head impact events, head injury assessment, concussion.

Posted Date: June 16th, 2021

DOl: https://doi.org/10.21203/rs.3.rs-588943/v1

License: (c) (1) This work is licensed under a Creative Commons Attribution 4.0 International License. Read Full License 


\section{Abstract \\ Background}

The tackle is the in-game activity carrying the greatest risk for concussion in Rugby. A recent evaluation of tackle characteristics in Rugby Union precipitated a rule modification to reduce head impact risk during tackles. This study aims to replicate the work conducted in Rugby Union by examining the association between tackle characteristics and head injury events in professional Rugby League.

\section{Methods}

We reviewed and coded 446 tackles resulting in a head injury assessment (HIA) and 5,694 tackles that did not result in a head injury from two National Rugby League (NRL) seasons. Tackle height, body position of players, and contact area on an opponent's body were evaluated, with the propensity of each situation to cause an HIA calculated as HIAs per 1000 events.

\section{Results}

The propensity for tacklers to sustain a head injury was 0.99 HIAs per 1000 tackles, 1.74 -fold greater than for the ball carrier ( 0.57 HIAs per 1,000 tackles). There was a 3.2-fold higher risk for an HIA when the tackler was upright compared to bent-at-the-waist. The greatest risk of a tackler HIA occurred when head contact was very low (knee, boot) or high (head and elbow). HIAs were most common following head-tohead impacts. The lowest propensity for tackler HIA was found when the tackler's head was in proximity with the ball carrier's torso.

\section{Conclusions}

The result of this study replicated the findings in professional rugby union. This has implications for the injury prevention initiatives implemented to reduce HIA risk because the majority of injuries are sustained by the player initiating the action.

\section{Key Points}

The tackler is more likely to sustain a head injury than the ball carrier.

Upright tackles result in a higher proportion of head-to-head contact.

The HIA risk is lowest when players are bent in the tackle.

Injury prevention initiatives aimed at reducing the tackle height might reduce the HIA risk. 


\section{Introduction}

Rugby league is an international full-contact collision sport that involves numerous tackle events. The tackle has been identified as the game event most commonly associated with clinically diagnosed concussion in professional rugby league. ${ }^{1}$ Video analysis of concussion in rugby league ${ }^{2-6}$ has revealed that the tackler is more frequently concussed than the ball carrier, and that head-to-head and head-toshoulder contact in upper body tackles, and head-to-hip contact in lower body tackles are the most frequent mechanism for head impact events in concussed tacklers. ${ }^{2-6}$ In professional rugby union (a fullcontact collision sport similar to rugby league), (i) upright tacklers with higher contacts on the ball carrier's body, (ii) tackler speed, and (iii) acceleration have been found to result in greater propensity for head injury events ${ }^{7,8}$ and concussions. ${ }^{9}$ Consideration of the tackler's and ball carrier's body positions, nature of head contact, and the ball carrier's evasion method are all variables that may play a role in modifying the risks for head injury. ${ }^{9}$ In particular, the finding that upright body position and higher contact tackles were more likely to cause HIAs drove injury prevention initiatives including emphasis on current tackle height laws and potential law changes in an attempt to create more tackles where the tackler adopts a bent at the waist body position and avoids tackles where head-to-head contact is likely. ${ }^{10}$ Given the findings regarding head injury risk during tackles in professional rugby union, and the game play similarities between the two rugby codes, the current study sought to replicate the Rugby Union studies in professional Rugby League. The primary objective of this study was to examine the association between tackle height and player body position in the tackle, with the goal to identify findings that might be useful for future injury prevention initiatives in the National Rugby League.

\section{Methods}

\section{Participants}

This case-control study was conducted in the National Rugby League over two seasons (2017 and 2018). The NRL includes sixteen clubs that compete over a 24-game season and a four-week postseason between eight qualifying teams. Therefore, during the regular season, there are 192 regular season matches (8 pairs of teams, each playing in 24 games) and nine playoff matches, resulting in a total of 402 matches in the study cohort. In accordance with the NRL and Rugby League Players Association Collective Bargaining Agreement, all athletes consented a priori to have their deidentified injury data used in research endorsed by the Rugby League Research Committee. The study was endorsed by the Rugby League Research Committee and approved by the institution human ethics committee.

\section{Procedures}

Head injury events (HIEs) were detected through the NRL's in-game injury surveillance system. For the 2017 and 2018 seasons there were two levels of in-game injury surveillance: (i) a sideline injury surveillance (SIS) system and (ii) the team medical staff. All HIEs identified by either the (i) SIS, or (ii) team doctor, were recorded and uploaded to the GamePlan Application. A Head Injury Assessment (HIA) 
was identified as a head impact event that necessitated either the permanent removal from the game of a player with a confirmed concussion, or the temporary removal of a player with a suspected concussion for an off-field head injury evaluation, as per the NRL concussion recognition and management process.

HIAs were selected as the criteria for a head injury case because these are discrete events that are sufficient to cause a player to be removed from play with suspected or confirmed concussion, in large enough numbers to power the analysis. The HIAs also have implications for match-play because they cause either the permanent removal of a player with a concussion from the game, or a fifteen-minute temporary interchange during which time the player undergoes the off-field evaluation. It is thus relevant for the sport to assess what factors contribute to these in-game disruptions.

Video footage of head impact events was clipped and loaded on the GamePlan Application. The first author was provided access to the NRL's GamePlan Application subscription and all video clips by the NRL. Most clips provided multiple camera angles of the event, in normal speed and in slow motion. The first author reviewed all video clips and coded all variables, in accordance with the procedure applied by Tucker and colleagues, ${ }^{7,8}$ using a predefined coding matrix (Table 1, Supplementary material). The coding matrix comprised 36 categorical variables, the majority of which described characteristics of the tackle but also included pre-tackle characteristics (Table 1, Supplementary material). The coding matrix was developed from the templates used in professional rugby union $9,11-13$ and our own work in professional rugby league ${ }^{6}$, and in consultation with coaches and researchers familiar with the field of research.

For this study, the focus was on technical elements of the tackler and ball carrier's actions, and the resultant head impacts. We report the body position of the tackler and ball carrier, head contact of the injured player with the opponent during the tackle, and the evasion method used by the ball carrier. The options coded within each of these categories are summarized in Supplementary Table 1.

In addition, a control group of 5,694 tackles that did not result in concussion were coded from 8 randomly selected games from the 2017 and 2018 seasons. A tackle was defined as 'any event where one or more tacklers attempted to stop or impede the ball carrier whether or not the ball carrier was brought to ground.' The control tackles were coded by the same analyst, and they were used to calculate the frequency of each tackle characteristic in normal match play. This enabled calculation of the propensity of a given tackle scenario to cause an HIA in injuries per 1000 events of each type.

Tackle events were excluded from analysis if (i) the quality of the video footage did not allow the tackle elements to be clearly identified or observed or (ii) the video footage was of insufficient quality to apply the coding template to the tackle. In some tackles, only one variable from the coding matrix could not be clearly identified. To ensure larger sample size, these cases were kept in the cohort, and thus the total number of tackles analysed for each tackle characteristic may vary by small amounts, as reported in the results.

\section{Data Analysis}


The event risk or propensity, in HIAs per 1000 tackles for each tackle characteristic, was calculated by dividing the number of HIA events occurring from that tackle characteristic by the total number of that tackle characteristic (obtained from the control cohort) and multiplying by a thousand. The incidence of HIAs was calculated as the period in matches per HIA for each tackle characteristic.

Data are presented as means and $95 \%$ Cls. The probability of each tackle characteristic being associated with a player undergoing an HIA was assessed using a Poisson regression with a log link function, using exposure to the characteristic as the offset variable to compare predictor/independent variables. Incident rate ratios (IRRs) were calculated to compare the propensity of two events by expressing the calculated HIA propensity relative to one another. Data were analysed using a standard statistical package (SPSS, Version 24.0), and a conventional type 1 error rate of 0.05 was used, with statistical significance accepted when the $95 \%$ Cls did not overlap.

\section{Results}

\section{Overall summary}

A total of 472 HIAs were identified and coded during the analysis period. Of these, 446 (94.5\%) occurred during tackles, with the remaining 26 occurring during open play and off-the-ball collisions. The 446 tackles were explored in detail for subsequent analysis. Overall HIA propensity during tackles was 1.56 HIAs per 1000 tackles (95\% $\mathrm{Cl} 1.42$ to 1.71$)$, with a tackle HIA occurring every 0.90 matches $(95 \% \mathrm{Cl} 0.82$ to 0.99 ). There were $283 \mathrm{HIAs}$ that occurred to tacklers, who were 1.7 times more likely to experience HIAs than ball carriers (163 HIAs). Tackler propensity was 0.99 tackler HIAs per 1000 tackles (0.88 to 1.11) compared to 0.57 ball carrier HIAs per 1000 tackles (0.49 to 0.66 ).

\section{Player body position}

The propensity and period for HIAs as a function of player body position is shown in Figure 1. Three tackles were omitted from the analysis because a tackler body position could not be determined from available video footage. Upright body positions for both tacklers and ball carriers created the greatest risk of HIAs. Upright tacklers were observed in $67 \%$ of all tackle HIAs, with an HIA involving an upright tackler every 1.36 matches (1.22 to 1.53 ) with a propensity of $2.55 \mathrm{HIAs}$ per 1000 tackles (2.28 to 2.96). The propensity for an HIA was 3.2 fold greater when tacklers were upright compared to bent at the waist ( 0.80 HIAs per 1000 bent tackles, 0.66 to 0.98 ), a situation that occurred every 4.14 matches (3.40 to 5.06). For falling or diving tacklers, propensity was 1.02 HIAs per 1000 falling/diving tackles ( 0.78 to 1.34$)$, with a period of 7.88 matches (5.99 to 10.37).

When evaluating risk for various ball carrier body positions, propensity was greatest when ball carriers were upright (2.45 HIAs per 1000 tackles, 2.28 to 2.86), compared to both bent-at-the-waist ( $0.16 \mathrm{HIAs}$ per 1000 tackles, 0.09 to 0.27$)$ and falling or diving (1.70 HIAs per 1000 tackles, 1.33 to 2.17 ) ball carriers. HIA incident rates were greatest for upright ball carriers (1.10 matches, 0.99 to 1.22$)$, followed by 
falling/diving ball carriers (6.28 matches, 4.92 to 8.03 ) and bent at the waist ball carriers (which were least likely to occur; every 30.92 matches, 17.96 to 53.26$)$.

\section{Player body position and injured player}

The influence of player body position for HIAs occurring specifically to the tackler and ball carrier are explored in Table 1. When the tackler experienced the HIA (282 HIAs with adequate video footage), 160 (57\%) occurred when the tackler was upright. Upright tacklers produce the highest propensity and incidence for tackler HIAs (Table 1), with upright tacklers 1.9 times more likely to experience HIAs than bent tacklers, and 1.4 times more likely to experience HIAs than diving tacklers. When the HIA occurred to the ball carrier $(n=161)$, the greatest propensity and incidence were also observed for upright tacklers (1.17 ball carrier HIAs per 1000 upright tacklers, 0.99 - 1.34, with a period of 2.98 matches per ball carrier HIA $(2.52-3.52))$.

The propensity for head injury to each player was similarly affected by ball carrier body position. The greatest propensity for an HIA for both tackler and ball carrier occurred when the ball carrier was upright (1.63 tackler HIAs per 1000 upright ball carriers and 0.81 ball carrier HIAs per 1000 upright ball carriers, Table 1).

\section{Interaction of tackler and ball carrier body positions}

We next explored how the HIA propensity and incidence were affected by interactions of tackler and ball carrier body position (Figure 2A). When both players in the tackle were upright, the HIA propensity was 2.64 HIAs per 1000 such tackles (2.34 to 2.98). This was similar to the propensity for tackles where the tackler was upright and the ball carrier was falling/diving (labelled "other" in the figure, 2.69 HIAs per 1000 tackles, $95 \% \mathrm{Cl} 1.85$ to 3.90$)$ and tackles with bent tacklers and upright ball carriers (2.27 HIAs per 1000 tackles, $95 \% \mathrm{Cl} 1.82$ to 2.82 ).

The incidence of these highest propensity body position interactions was however different (Figure 2B). The highest incidence occurred when both tacklers and ball carriers were upright (every 1.57 matches, 1.39 to 1.77). For a bent tackler and upright ball carrier, an HIA occurred every 4.96 matches (3.99 - 6.17), while an upright tackler and falling/diving ball carrier produced an HIA every 14.36 matches (9.91 20.79).

The lowest propensity and incidence occurred for tackles where both the tackler and the ball carrier were bent ( 0.05 HIAs per 1000 tackles, with a period of one every 134 matches). This situation accounted for only three HIAs ( $<1 \%$ of the total), despite comprising $22 \%$ of all tackles in the control cohort (Fig $2 \mathrm{~A}$, note this has been omitted from Fig 2B for clarity of comparison with more common HIA mechanisms).

\section{Head contact with opponent}

Table 2 shows the HIA propensity and incidence for various head contacts with the opponent in tackles, with tackler and ball carrier HIAs considered separately. The highest propensity for tackler HIAs occurred 
when the tackler's head struck the ball carrier's elbow, boot, or knee, while head contact with the playing surface also resulted in a high risk of tackler HIAs. HIAs from these impacts were however rare, accounting for $25(9 \%), 12(4 \%), 17(6 \%)$ and $5(2 \%)$ of tackler HIAs, respectively. Their incidence was thus low (Table 2).

The highest incidence was found for impacts between the tackler's head and the ball carrier's shoulder and head. These head to head and head to shoulder impacts have a relatively low propensity to cause HIAs (0.64 HIAs per 1000 tackles, 0.50 to 0.81 for shoulder) and a moderately high propensity for HIA (10.31 tackler HIAs per 1000 tackles, 7.95 to 13.33 for head), respectively, but because they occur so frequently in the sport, the HIA incidence from these impacts was low (Table 2).

The lowest propensity for HIAs was observed when the tackler's head contacted the ball carrier's torso. This situation also resulted in the lowest tackler HIA incidence, with a tackler HIA every 134 matches (43.22 - 415.48, Table 2).

For ball carrier HIAs, propensity was greatest for ball carrier contact with the tackler's elbow, boot, forearm and head (Table 2), and lowest for contact with the tackler's torso, hand and shoulder. As was observed for tackler HIAs, the contact types with the highest propensity (elbow, boot and forearm) were rare, accounting for 11 of the 162 ball carrier HIAs (6.8\%), while the most common contact types resulting in HIAs were ball carrier contact with the shoulder (49 HIAs, 30.2\%), arm (30 HIAs, 18.5\%) and head (27 HIAs, $16.7 \%)$.

\section{Discussion}

This study explored how the body position of the tackler and ball carrier was associated with the propensity and incidence of HIAs to both players during tackles in the National Rugby League. Our first important finding, consistent with previous research, ${ }^{7-9}$ is that the tackler is 1.7 times more likely to require a HIA from a tackle than the ball carrier. Of the $446 \mathrm{HIAs}, 63 \%$ occurred to the tackler. This is a finding similar to that observed in rugby union. ${ }^{7}$ This has implications for the injury prevention initiatives designed to reduce risk for HIAs. The application of law typically protects players from the actions of their opponents. However, our data, like that in Rugby Union, shows that the majority of injuries happen to the player initiating, not receiving, the action (i.e., the tackler).

To explore this further, we focused on the body position of the players in the tackle, because it had previously been shown that an upright tackler creates significantly more risk of an HIA than a bent tackler. ${ }^{7}$ Our second important finding is to confirm this for Rugby League, where the overall propensity for an HIA was 3.2-fold higher when the tackler was upright compared to bent-at-the-waist, and 2.1-fold greater than for a falling/diving tackler (Figure 1). The result is an HIA from upright tacklers every 1.36 matches, compared to one every 4.14 matches for a bent tackler. Because these two body positions account for $83 \%$ of all tackles, their relative risks are most important for risk mitigation considerations. 
Similarly, we find that HIA propensity and incidence are highest when the ball carrier is upright (Figure 1). Notably, when we explored the HIA risk to each player in the tackle as a function of their body position, we confirm that the overall risk is greatest when tacklers are upright, but also find that this highest risk exists for both the tackler and the ball carrier specifically (Table 1). Upright tacklers thus create greatest risk to themselves, with an HIA propensity that remains 1.9-fold greater than when the tackler is bent-at-the waist (Table 1), as well as to their opponent ball carrier, whose risk is increased by a factor of 12.8 when the tackler is upright (Table 1 ).

Naturally, the interaction between the tackler's body position that the body position of ball carriers is an important factor to consider. Here, we have explored many possible interactions between upright, bent-atthe-waist, and other player positions (comprised of falling/diving, jumping kicking, lying and slipping). This analysis confirms that when both players are upright the HIA propensity is greater than (i) when both players are bent in the tackle, and (ii) when the tackler is upright and the ball carrier is bent. Indeed, for any ball carrier body position, the HIA risk was greatest when the tackler was upright, and for any tackler body position, the HIA risk was lowest when the ball carrier was bent. While the specific interactions did not always reach significance (Fig 1), the implication is clear, and consistent with what was found in rugby union ${ }^{7}$ - the safest body position is when the tackler and ball carrier are bent, and no specific interaction changes this relative risk profile, though certain interactions create similar risk. Overall, however, bent players are considerably less likely to cause head injuries during tackles.

This can be understood when assessing the location of head contact with the opponent that is responsible for causing the HIA. Here, we have examined the HIA risk to the tackler and the ball carrier separately (Table 2). Unsurprisingly, the greatest HIA propensity occurs, generally, for head contact with a hard, bony surface like an elbow, boot, knee or head of the opponent (Table 2). The very highest propensity impacts are however relatively rare, and thus have a low incidence.

Significantly more frequently, tacklers were injured by head-to-head (moderate propensity) and head-toshoulder (low propensity) impacts, while ball carriers were injured by head-to-head, head-to-arm, and head-to-shoulder impacts (Table 2). Collectively, these findings indicate that tackles where the head is very low (knee or below) or very high (head height) create significantly more risk, with the safest zone at the level of the opponent's torso.

The game play risks and their association with HIAs caused by the various head contact locations can be understood when appreciating that player body position exposes players to situations where their heads are more likely to encounter higher risk contact locations. That is, given the high propensity of head-tohead, head-to-elbow, head-to-knee, and head-to-arm impacts to cause HIAs (Table 2), the player body position that creates higher likelihoods of these impact locations is going to produce the highest HIA propensity. This occurs when players are upright, as we have shown (Figure 1), or very low (diving to the opponent's knee). 
The strategy that may be explored by regulators to reduce injury risk is therefore to drive tackle technique or execution changes that prevent or reduce the likelihood of head-to-head, head-to-elbow, and head-toknee impacts. Instead, it would be desirable for heads to be in proximity with, and to make contact with, the torso or the shoulder of an opponent in the tackle, because the HIA propensity for these contacts is very low (Table 2). Importantly, even though the HIA incidence from head-to-shoulder impacts is high (period of 6.09 and 8.20 matches for tacklers and ball carriers, respectively), they are low in risk or propensity (Table 2), indicating the interplay between the frequency of an event and its inherent risk. Therefore, if tacklers and ball carriers were to tackle in such a way as to substitute the highest risk headto-head, head-to-elbow and head-to-knee impacts for impacts with lower risk at the torso or shoulder, the overall number of head injuries during tackles will decrease. This concept, where one behaviour is substituted for another, requires identification of the behaviour with the higher propensity, so that it can be replaced by the identified safer and thus desirable behaviour with the lower propensity.

In this study, we clearly describe a combination of player body positions and head impact locations that span this spectrum from low propensity (bent players, head impacts with the torso of the opponent) to high propensity (upright players and head impacts with opponent's heads, or diving players and head impacts with opponent's knees and feet).

Applying this concept to the body position findings we describe previously, it would thus be desirable for tacklers and ball carriers to more often be bent at the waist, with fewer instances where they are upright. This should reduce the overall number of HIAs because the higher risk behaviour (upright players) is substituted with the lower risk behaviour (bent players). It must be cautioned, however, that if the tackler is too low the risk may increase again as a result of more frequent head to knee and head to boot contacts, which we also found to be high in risk, though very rare. Finally, the elbow-to-head scenario we find to have the highest propensity may be reduced through technique training and law interventions to prevent the use of the elbow on opponent's heads.

The relatively greater propensity for an HIA when players are upright is in part the result of their head proximity to the higher risk body parts of their opponents (heads and elbows, see Table 2), but may also be the result of dynamic elements and biomechanical factors in the tackle that are beyond the scope of this analysis. For instance, it may be that a bent tackler, whose head is in front of their body while their neck is braced, is less susceptible to the neck forces and head accelerations that can cause a concussion. ${ }^{14}$ Tierney and colleagues ${ }^{14}$ have demonstrated, using a passive biomechanical model, that head and neck kinematics and mechanics are significantly affected by the area of contact, with higher linear and angular acceleration of the head for ball carrier during upright, higher contacts. ${ }^{14}$ Such a phenomenon may contribute to our findings, and may be further moderated by the relative head and neck position of each player when bent at the waist. Also, the context of the tackle may change, with elements of speed, acceleration, direction and tackle technique altered when players are bent compared to upright.

\section{Limitations}


There are a number of limitations in the current study. First, the interpretation and coding of the tackle variables are subjective. All events were coded by one analyst to avoid any considerations of betweenrater differences, though the subjective nature represents a potential source of error in the analysis. The present method of analysis employs a discreet approach to identify specific tackle characteristics that may be the target of risk mitigation strategies. The characteristics do however interact with one another, and while in this study we have attempted to explore these interactions for body position, head contact and ball carrier evasion method, the tackle is a dynamic and complex event during which many factors may affect risk in subtle ways. Third, a number of the tackle variables occurred rarely, leading to sparse data, and should be interpreted with caution. Third, the results may not be generalisable to other levels of play or women players.

\section{Summary And Conclusions}

We show that the tackler is more likely to sustain a head injury than the ball carrier, and that this risk is greatest when both players are upright, both to the tackler and the ball carrier. Risk is lowest when players are bent in the tackle, the result of which is that head contact is more likely to occur between a player's head and the torso and shoulder of an opponent, rather than high risk and frequency head-to-head contacts, and high-risk head-to-knee and head-to-boot impacts. We find that this bent position is generally safer for any head contact and any ball carrier evasion method, with few circumstances where being upright reduces the risk compared to being bent at the waist. The implication is that risk mitigation that brings players' heads out of high-propensity locations that occur when tackling too high or too low may contribute to a reduction in overall head injury risk in Rugby League. This can be achieved in large part by preventing upright tackles that result in head to head proximity and impacts, aiming instead for a slight lowering of height to produce head-to-torso contacts and proximities, while still emphasizing the risk of excessively low tackles that increase the likelihood of head to knee and boot impacts. Tackle technique education and training to achieve these desired outcomes given the dynamic and complex nature of the sport could help reduce head injuries.

\section{How might it impact on clinical practice in the future?}

This study replicates in rugby league prior findings from rugby union relating to tackle characteristics and concussion risk. Rugby union has introduced intervention strategies, through rule modifications, to try to reduce concussion risk. It might be useful to explore sanction reinforcement and change, as well as coaching methods for reducing the occurrence of upright tackles, which are shown to result in a high proportion of head injuries.

\section{List Of Abbreviations}

HIA

Head Injury Assessment

$N R L$ 
National Rugby League

SIS

Sideline Injury System

\section{Declarations}

Ethical Approval and Consent to Participate: This study was approved by the Institutional Review Board at The University of Newcastle (Ref No. H-2012-0344).

Consent for Publication: Not Applicable.

Availability of Data and Materials: The statistical analyses and underlying data supporting the conclusions of this article will be made available by the authors to qualified researchers for research purposes, without undue reservation.

Competing Interests: AJG serves as a scientific advisor for hitlQ, Ltd. He has a clinical practice in neuropsychology involving individuals who have sustained sport-related concussion (including current and former athletes). He has been a contracted concussion consultant to Rugby Australia since July 2016. He has received travel funding or been reimbursed by professional sporting bodies, and commercial organisations for discussing or presenting sport-related concussion research at meetings, scientific conferences, workshops, and symposiums. Previous grant funding includes the NSW Sporting Injuries Committee, the Brain Foundation (Australia), an Australian-American Fulbright Commission Postdoctoral Award, a Hunter New England Local Health District, Research, Innovation and Partnerships Health Research \& Translation Centre and Clinical Research Fellowship Scheme, and the Hunter Medical Research Institute (HMRI), supported by Jennie Thomas, and the HMRI, supported by Anne Greaves. AJG is supported by a National Health and Medical Research Council (NHMRC) Early Career Fellowship and the Priority Research Centre for Stroke and Brain Injury, School of Medicine and Public Health, The University of Newcastle. He acknowledges unrestricted philanthropic support from the National Rugby League for research in retired professional rugby league players.

GLI has a clinical and consulting practice in forensic neuropsychology, including expert testimony, involving individuals who have sustained mild TBIs (including athletes). He has received research funding from several test publishing companies, including ImPACT Applications, Inc., CNS Vital Signs, and Psychological Assessment Resources (PAR, Inc.). He has received research support from the Harvard Integrated Program to Protect and Improve the Health of NFLPA Members, and grant support from the National Football League. He serves as a scientific advisor for Sway Operations, LLC, Highmark, Inc., and BioDirection, Inc.

RT is employed by World Rugby.

Funding: This study was funded in part by the Priority Research Centre for Stroke and Brain Injury. Unrestricted philanthropic support was provided by ImPACT Applications, Inc., the Mooney-Reed 
Charitable Foundation, and the Spaulding Research Institute. The funders were not involved in the study design, collection, analysis, interpretation of data, the writing of this article or the decision to submit it for publication.

Authors' Contributions: AJG and RT conceived and designed the study and coding template. AJG coded all video clips for analysis and RT conducted the analysis of the data. AJG, GLI, SE, and RT interpreted the data. AJG, GLI, and RT prepared the first draft of the manuscript and then all authors made substantial contributions to the various iterations of the manuscript resulting in the final version.

Acknowledgements: The authors acknowledge and appreciate the support and endorsement of the Rugby League Research Committee in conducting this study.

\section{Authors' Information:}

Twitter: Professor Ross Tucker @ScienceofSport; Dr Suzi Edwards @Suzi_Edwards

\section{References}

1. Gardner A, Iverson GL, Levi CR, et al. A systematic review of concussion in rugby league. Br J Sports Med. 2015;49(8):495-8.

2. Gardner AJ, Iverson GL, Quinn TN, et al. A preliminary video analysis of concussion in the National Rugby League. Brain Inj. 2015;29(10):1182-5.

3. Gardner AJ, Kohler RMN, Levi CR, Iverson GL. Usefulness of Video Review of Possible Concussions in National Youth Rugby League. Int J Sports Med. 2017;38(1):71-5.

4. Gardner AJ, Wojtowicz M, Terry D, Levi CR, Zafonte RD, Iverson GL. Video and Clinical Screening of Australian National Rugby League Players Suspected of Sustaining Concussion. Brain Inj. 2017;31(13-14):1918-24.

5. Gardner AJ, Howell DR, Iverson GL. A video review of multiple concussion signs in National Rugby League match play. Sport Med - Open. 2018;4(1):5.

6. Gardner AJ, Howell DR, Levi CR, Iverson GL. Evidence of Concussion Signs in National Rugby League Match Play: a Video Review and Validation Study. Sport Med - Open. 2017;3(1):29.

7. Tucker R, Raftery M, Kemp S, et al. Risk factors for head injury events in professional rugby union: A video analysis of 464 head injury events to inform proposed injury prevention strategies. $\mathrm{Br} \mathrm{J}$ Sports Med. 2017;51(15):1152-7. doi:10.1136/bjsports-2017-097895.

8. Tucker R, Raftery M, Fuller GW, Hester B, Kemp S, Cross MJ. A video analysis of head injuries satisfying the criteria for a head injury assessment in professional Rugby Union: a prospective cohort study. Br J Sports Med. 2017;51(15):1147-51.

9. Cross MJ, Tucker R, Raftery M, et al. Tackling concussion in professional rugby union: a casecontrol study of tackle-based risk factors and recommendations for primary prevention. $\mathrm{Br} J$ Sports Med. 2017:Epub ahead of print. 
10. Raftery M, Tucker R, Falvey ÉC. Getting tough on concussion: how welfare-driven law change may improve player safety-a Rugby Union experience. Br J Sports Med. 2020:in press. doi:10.1136/bjsports-2019-101885.

11. Fuller CW, Ashton T, Brooks JHM, Cancea RJ, Hall J, Kemp SPT. Injury risks associated with tackling in rugby union. Br J Sports Med. 2010;44(3):159-67.

12. McIntosh AS, Savage TN, McCrory P, FréchÈde BO, Wolfe R. Tackle characteristics and injury in a cross section of rugby union football. Med Sci Sports Exerc. 2010;42(5):977-84.

13. Quarrie KL, Hopkins WG. Tackle injuries in professional rugby union. Am J Sports Med. 2008;36(9):1705-16.

14. Tierney GJ, Simms CK. Can tackle height influence head injury assessment risk in elite rugby union? J Sci Med Sport. 2018;21(12):1210-4.

\section{Tables}


Table 1

Propensity for HIAs for tacklers and ball carriers as a function of body position.

\begin{tabular}{|c|c|c|c|c|}
\hline & $\begin{array}{l}\text { HIA } \\
\text { events }\end{array}$ & $\begin{array}{l}\text { Propensity (HIAs per 1,000 } \\
\text { events) }\end{array}$ & $95 \% \mathrm{Cl}$ & $\begin{array}{l}\text { Incidence (matches } \\
\text { per HIA) }\end{array}$ \\
\hline \multicolumn{5}{|c|}{ HIAs as a function of tackler body position } \\
\hline \multicolumn{5}{|l|}{ Tackler HIAs } \\
\hline For upright tackler & 160 & 1.38 & $\begin{array}{l}1.19- \\
1.62\end{array}$ & 2.51 \\
\hline For bent tackler & 86 & 0.71 & $\begin{array}{l}0.58- \\
0.88\end{array}$ & 4.67 \\
\hline $\begin{array}{l}\text { For falling/diving } \\
\text { tackler }\end{array}$ & 36 & 0.72 & $\begin{array}{l}0.52- \\
1.00\end{array}$ & 11.17 \\
\hline Total Tackler HIAs & 282 & 0.99 & $\begin{array}{l}0.88- \\
1.11\end{array}$ & \\
\hline \multicolumn{5}{|l|}{ Ball carrier HIAs } \\
\hline For upright tackler & 135 & 1.17 & $\begin{array}{l}0.99- \\
1.38\end{array}$ & 2.98 \\
\hline For bent tackler & 11 & 0.09 & $\begin{array}{l}0.05- \\
0.16\end{array}$ & 36.55 \\
\hline $\begin{array}{l}\text { For falling/diving } \\
\text { tackler }\end{array}$ & 15 & 0.3 & $\begin{array}{l}0.18- \\
0.50\end{array}$ & 26.80 \\
\hline Total Ball Carrier HIAs & 161 & 0.56 & $\begin{array}{l}0.48- \\
0.66\end{array}$ & \\
\hline \multicolumn{5}{|c|}{ HIAs as a function of ball carrier body position } \\
\hline \multicolumn{5}{|l|}{ Tackler HIAs } \\
\hline For upright ball carrier & 244 & 1.63 & $\begin{array}{l}1.44- \\
1.85\end{array}$ & 1.65 \\
\hline For bent ball carrier & 8 & 0.10 & $\begin{array}{l}0.05- \\
0.20\end{array}$ & 50.25 \\
\hline $\begin{array}{l}\text { For falling/diving ball } \\
\text { carrier }\end{array}$ & 29 & 0.53 & $\begin{array}{l}0.37- \\
0.76\end{array}$ & 13.86 \\
\hline Total ball carrier HIAs & 281 & 0.99 & $\begin{array}{l}0.88- \\
1.11\end{array}$ & \\
\hline
\end{tabular}

Note. Cl: confidence interval; HIA: head injury assessment. 


\begin{tabular}{|c|c|c|c|c|}
\hline & $\begin{array}{l}\text { HIA } \\
\text { events }\end{array}$ & $\begin{array}{l}\text { Propensity (HIAs per 1,000 } \\
\text { events) }\end{array}$ & $95 \% \mathrm{Cl}$ & $\begin{array}{l}\text { Incidence (matches } \\
\text { per HIA) }\end{array}$ \\
\hline For upright ball carrier & 121 & 0.81 & $\begin{array}{l}0.68- \\
0.97\end{array}$ & 3.32 \\
\hline For bent ball carrier & 5 & 0.06 & $\begin{array}{l}0.03- \\
0.15\end{array}$ & 80.40 \\
\hline $\begin{array}{l}\text { For falling/diving ball } \\
\text { carrier }\end{array}$ & 35 & 0.63 & $\begin{array}{l}0.46- \\
0.88\end{array}$ & 11.49 \\
\hline Total Ball Carrier HIAs & 161 & 0.56 & $\begin{array}{l}0.48- \\
0.66\end{array}$ & \\
\hline
\end{tabular}


Table 2

Tackler and Ball Carrier HIAs for different contacts with opponent's body.

\begin{tabular}{|c|c|c|c|c|}
\hline & $\begin{array}{l}\text { HIA } \\
\text { events }\end{array}$ & $\begin{array}{l}\text { Propensity (HIAs per } 1000 \\
\text { events) }\end{array}$ & $95 \% \mathrm{Cl}$ & $\begin{array}{l}\text { Incidence (matches per } \\
\text { event) }\end{array}$ \\
\hline \multicolumn{5}{|c|}{ Tackler HIAs as a function of tackler's head contact with ball carrier } \\
\hline Head & 58 & 10.31 & $7.96-13.33$ & 6.93 \\
\hline Shoulder & 66 & 0.64 & $0.5-0.81$ & 6.09 \\
\hline Hip & 47 & 2.91 & $2.18-3.87$ & 8.55 \\
\hline Forearm & 5 & 0.22 & $0.09-0.52$ & 80.40 \\
\hline Elbow & 25 & 99.50 & $\begin{array}{l}67.23- \\
147.25\end{array}$ & 16.08 \\
\hline Arm & 7 & 2.14 & $1.02-4.49$ & 57.43 \\
\hline Hand & 14 & 3.36 & $1.98-5.66$ & 28.71 \\
\hline Torso & 3 & 0.03 & $0.01-0.1$ & 134.00 \\
\hline Thigh & 8 & 1.68 & $0.83-3.35$ & 50.25 \\
\hline Knee & 17 & 56.38 & $35.05-90.7$ & 23.65 \\
\hline Boot & 12 & 79.60 & $\begin{array}{l}45.2- \\
140.16\end{array}$ & 33.50 \\
\hline $\begin{array}{l}\text { Playing } \\
\text { surface }\end{array}$ & 5 & 99.50 & $\begin{array}{l}41.41- \\
239.06\end{array}$ & 80.40 \\
\hline Buttocks & 6 & 10.85 & $4.87-24.16$ & 67.00 \\
\hline Back & 8 & 0.23 & $0.11-0.45$ & 50.25 \\
\hline Unidentifiable & 2 & & & \\
\hline \multicolumn{5}{|c|}{ Ball carrier HIAs as a function of ball carrier's head contact with tackler } \\
\hline Head & 27 & 5.60 & $3.83-8.16$ & 14.89 \\
\hline Shoulder & 49 & 0.47 & $0.35-0.62$ & 8.20 \\
\hline Hip & 3 & 3.98 & $1.28-12.34$ & 134.00 \\
\hline Forearm & 9 & 8.96 & $4.65-17.21$ & 44.67 \\
\hline Elbow & 1 & 19.90 & $2.8-141.28$ & 402.00 \\
\hline Arm & 30 & 0.91 & $0.63-1.3$ & 13.40 \\
\hline
\end{tabular}

Note. Cl: confidence interval; HIA: head injury assessment. 


\begin{tabular}{|lllll|}
\hline & $\begin{array}{l}\text { HIA } \\
\text { events }\end{array}$ & $\begin{array}{l}\text { Propensity (HIAs per 1000 } \\
\text { events) }\end{array}$ & $95 \% \mathrm{Cl}$ & $\begin{array}{l}\text { Incidence (matches per } \\
\text { event) }\end{array}$ \\
\hline Hand & 6 & 0.17 & $0.07-0.37$ & 67.00 \\
\hline Torso & 10 & 0.10 & $0.05-0.17$ & 40.20 \\
\hline Thigh & 2 & 2.84 & $0.71-11.36$ & 201.00 \\
\hline Knee & 5 & 3.43 & $1.42-8.24$ & 80.40 \\
\hline Boot & 1 & 19.90 & $2.8-141.28$ & 402.00 \\
\hline $\begin{array}{l}\text { Playing } \\
\text { surface }\end{array}$ & 18 & & & \\
\hline Buttocks & 0 & 0.00 & & \\
\hline Back & 0 & 0.00 & & \\
\hline Ball & 0 & 0.00 & & \\
\hline Lower leg & 1 & & & \\
\hline Unidentifiable & 1 & & & \\
\hline Note. Cl: confidence interval; HIA: head injury assessment. & & \\
\hline
\end{tabular}

\section{Figures}



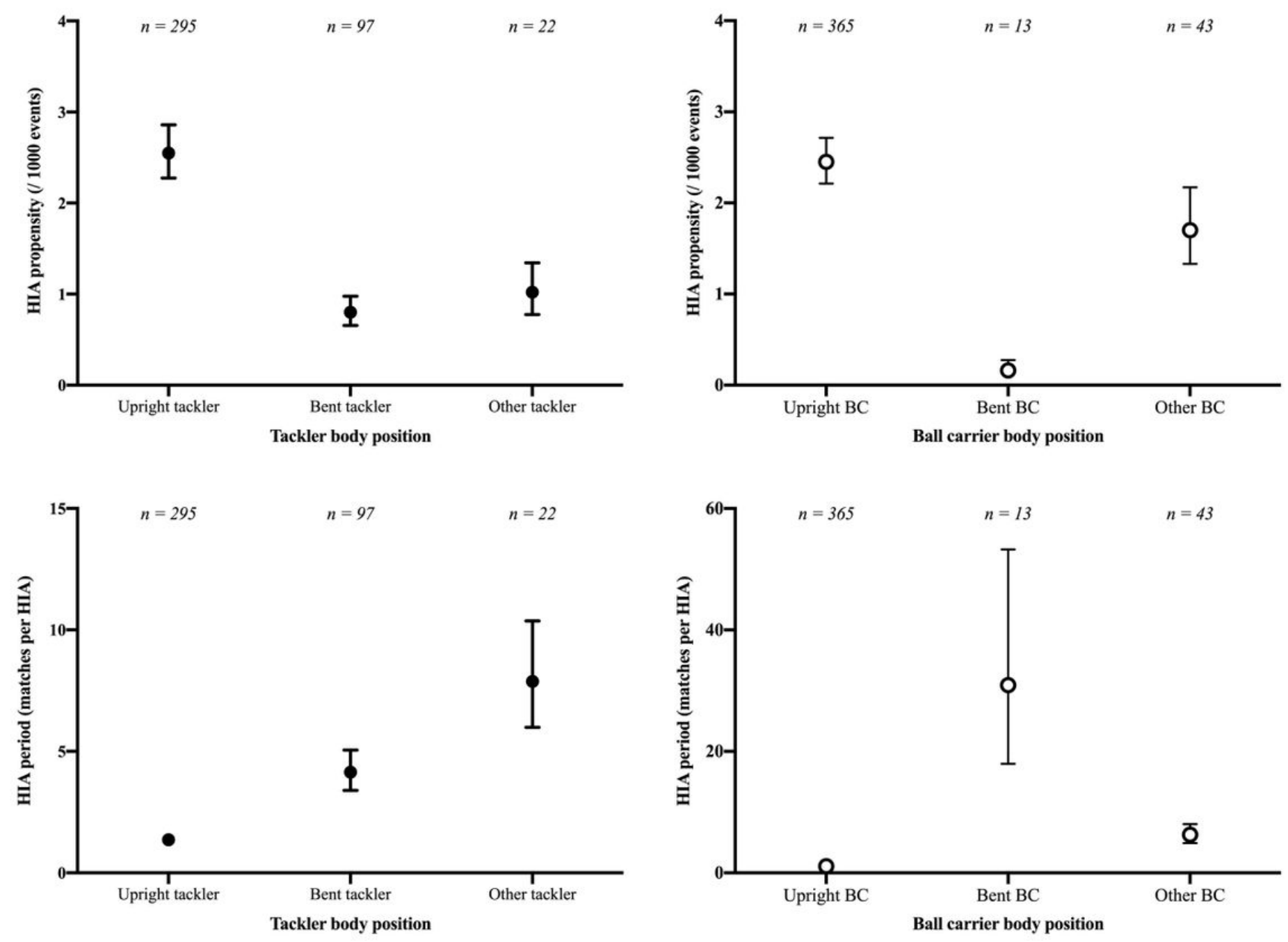

Figure 1

HIA propensity (top) and HIA (bottom) for tackler (left) and ball carrier (right) body positions. 


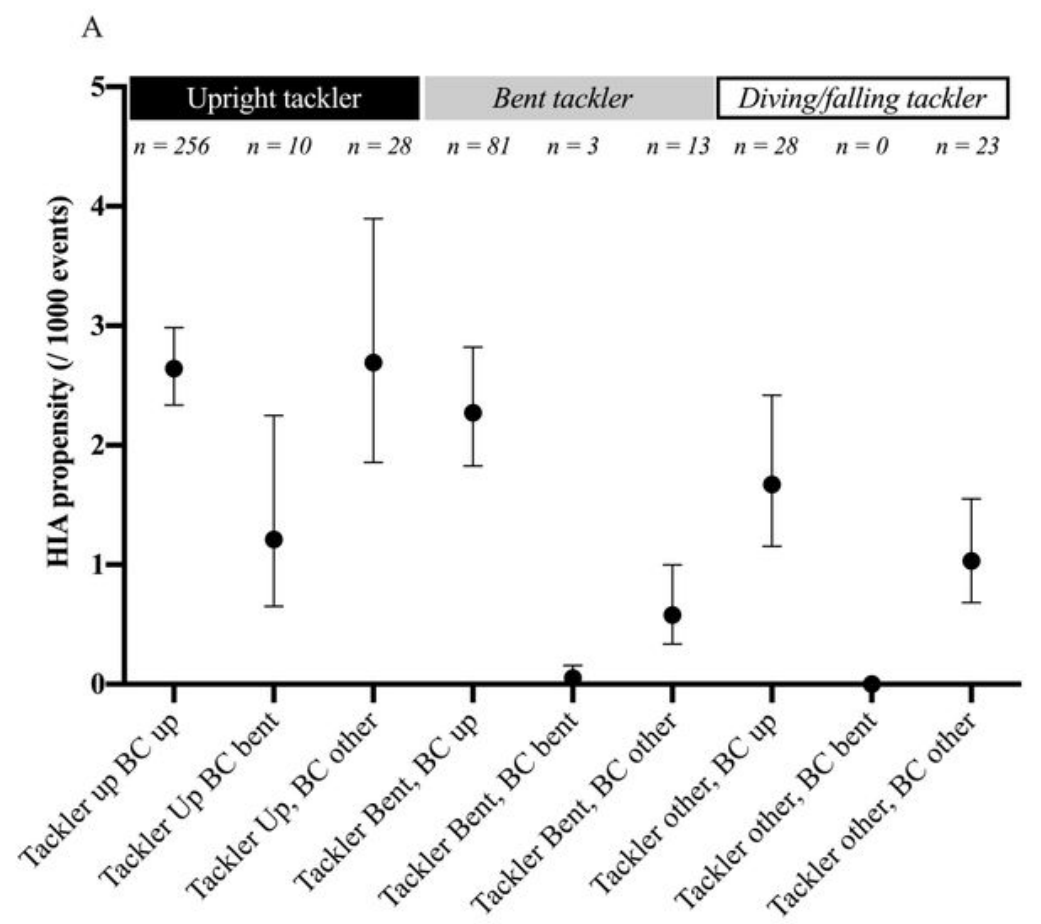

Player body position

B

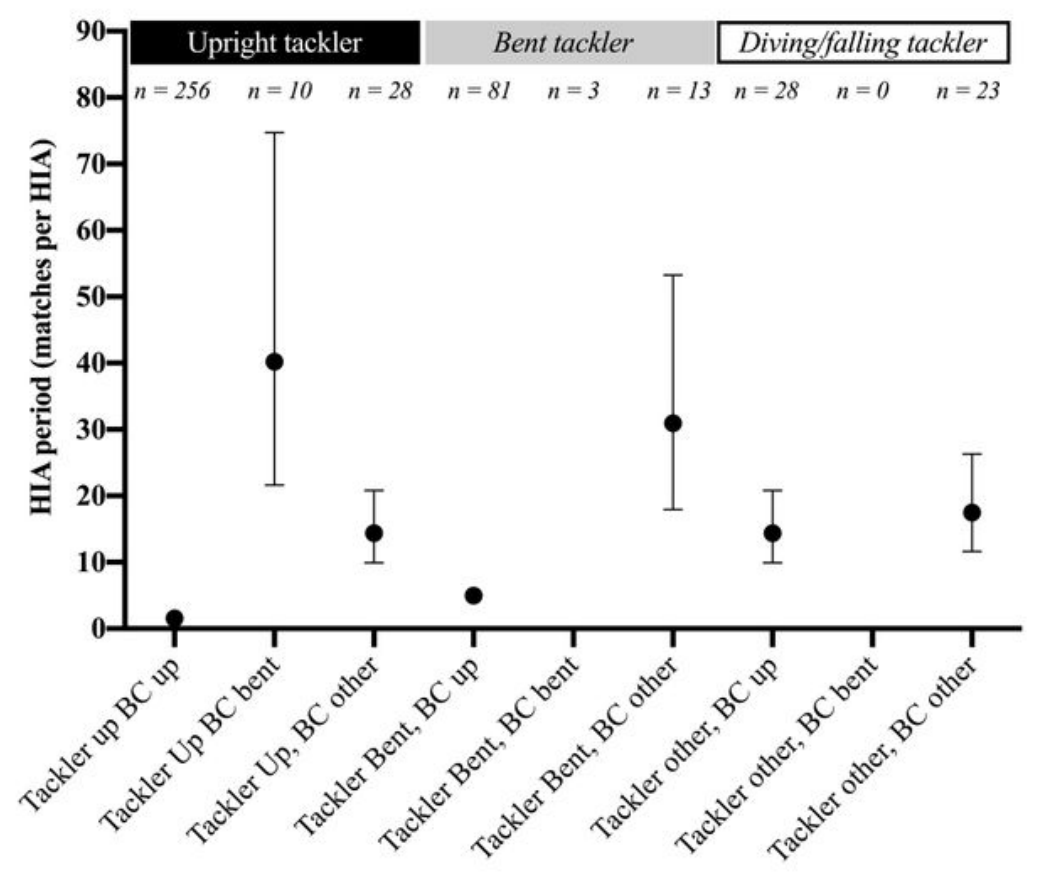

Player body position

Figure 2

HIA propensity (2A) and incidence (2B) of tackler and ball carrier body position interaction.

\section{Supplementary Files}

This is a list of supplementary files associated with this preprint. Click to download. 
- SupplementaryTableNRLtackleractionrisk.docx 